\title{
Validity and reliability testing of the Spanish version of the BESTest and mini- BESTest in healthy community-dwelling elderly
}

Pilar Dominguez-Olivan ${ }^{1,2^{*}}$, Angel Gasch-Gallen ${ }^{1}$, Esmeralda Aguas-Garcia² and Ana Bengoetxea ${ }^{3,4}$

\begin{abstract}
Background: The Balance Evaluation Systems Test (BESTest) and its abbreviated version, the Mini-BESTest are clinical examination of balance impairment, but its psychometric properties have not yet been tested in European Spanish. We aimed to assess the psychometric properties of BESTest and Mini-BESTest in Spanish in communitydwelling elderly people.
\end{abstract}

Methods: We designed a cross-sectional transcultural adaptation and validation study.

Convenience sample of thirty (N-30) adults aged 65 to 89 years old without balance problems were recruited. Two physiotherapists assessed participants at the same time. Internal consistency of Spanish BESTest and Mini-BESTest was carried out by obtaining the Cronbach Alpha. The reproducibility between raters was studied with the Intraclass Correlation Coefficient. The Pearson correlation coefficient was calculated by comparing the relationship between the BESTest, mini-BESTest, Berg Balance Scale (BBS) and Falls Efficacy Scale-International (FES-I).

Results: BESTest and Mini-BESTest showed good internal consistency. BESTest and Mini-BESTest total scores showed an excellent inter-rater agreement. There was a significant correlation between total score of the BESTest and the Mini-BESTest $(r=0.65 ; p<0.001)$. BESTest had a moderate association with BBS and a strong association with FES-I. Mini-BESTest had a fair correlation with BBS and FES-I. Total scores obtained by women at BESTest and at Mini-BESTest were significantly lower than those reached by men. The differences observed in all the test when disaggregating data by sex require further research.

Conclusions: Spanish versions of BESTest and Mini-BESTest are comprehensible for new raters. They are reliable tools to provide information on which particular balance systems show impairment in community dwelling older adults. Elderly women had a worse quality of balance and a greater perception of their risk of falling.

Trial registration: This study was registered in ClinicalTrials.gov with NCT 03403218 on 2018/01/17.

Keywords: BESTest, MiniBESTest, Spanish, Balance, Elderly, Reliability, Validity

\footnotetext{
* Correspondence: mpdomin@unizar.es

'IIS Aragón, Facultad de Ciencias de la Salud, Universidad de Zaragoza,

Zaragoza, Spain

${ }^{2}$ Hospital Universitario Miguel Servet, Zaragoza, Spain

Full list of author information is available at the end of the article
}

\section{$\triangle B M C$}

(c) The Author(s). 2020 Open Access This article is licensed under a Creative Commons Attribution 4.0 International License, which permits use, sharing, adaptation, distribution and reproduction in any medium or format, as long as you give appropriate credit to the original author(s) and the source, provide a link to the Creative Commons licence, and indicate if changes were made. The images or other third party material in this article are included in the article's Creative Commons licence, unless indicated otherwise in a credit line to the material. If material is not included in the article's Creative Commons licence and your intended use is not permitted by statutory regulation or exceeds the permitted use, you will need to obtain permission directly from the copyright holder. To view a copy of this licence, visit http://creativecommons.org/licenses/by/4.0/ The Creative Commons Public Domain Dedication waiver (http://creativecommons.org/publicdomain/zero/1.0/) applies to the data made available in this article, unless otherwise stated in a credit line to the data. 


\section{Background}

Motor control is defined as the ability to regulate or direct the mechanisms essential for balance and movement [1]. It is very complex and involves many different underlying systems. A system must be understood as a set of elements whose parts or components are related to at least some of the other components.

During ageing, motion initiation, postural control and movement are usually impaired by factors involving effectors, sensory and cognitive systems. Specifically for the vestibular system, above 70 years old, a decrease in the number of sensory vestibular cells and a reduction in vestibular nerve fibres and neurons in the vestibular nuclei has been described [2]. Visual function is also impaired, including reduction in visual acuity, depth perception and peripheral vision [3]. In the musculoskeletal system, osteoporosis, sarcopenia and reduction of body muscle strength are established effects to a greater or lesser extent. As regards the effects of ageing in cognition, selective attention is reported to be less effective in the elderly compared to young subjects. Among other degradations, an increase in the attentional cost of posture control and displacement has also been mentioned [4].

Falls are a geriatric syndrome derived from this deterioration and constitute one of the most frequent and potentially significant public health problems [5]. Although there is no clear indication of the factors that imply worse balance for men and women older than 65 years, there appears to be general agreement in the literature that old women have a worse balance than old men [6-8].

The potential of clinical measurements of balance is usually limited to identifying the risk of falling, within the elderly population. The Berg Balance Scale (BBS) is a widely used clinical scale for functional balance and is currently considered as a reference for assessing balance in people with risk of falling due to stroke or Parkinson's disease $[9,10]$.

Considered the gold standard, the BBS has been strongly evaluated as valid and reliable but there are still several factors that indicate that the BBS should be used in conjunction with other balance measures. There are few tasks in the BBS to test dynamic balance, which may limit its power to identify sensitive older adults from those who live independently in the community [10]. Also, ceiling effect and floor effect has been reported for the BBS when used with community dwelling older adults [7, 11]. The Falls Efficacy Scale- International (FES-I) is a measure of "fear of falling" or, more properly, "concerns about falling", which is also suitable for research and clinical practice. Stroke rehabilitation or Spanish studies about sarcopenic obesity or balance in the older people with instability include this instrument [12-14]. The identification of valid, reliable and clinically relevant outcome measures to document and evaluate the evolution or recovery of a health condition is vital in determining the effectiveness of interventions. The Balance Evaluation Systems Test (BESTest) and its abbreviated version (Mini-BESTest) are clinical balance tools that allow the identification of not only the risk of falling, but also which impairments are involved in dysfunctional balance. Having detected the degraded components underlying balance control, specific types of therapeutic intervention for different types of balance problems can be applied [10].

The BESTest has shown to have high correlation with functional gait and balance performance and moderate correlation with self-assessed fear of falling (FES-I) in English, its source language $[15,16]$.

However, clinical systems used all over the world must not only be translated, but must also be adapted culturally to maintain content validity at a conceptual level across different cultures [17]. Psychometric properties must also be preserved in the destination language. This makes it necessary to analyse its validity before dissemination [18].

The purpose of this study was to translate and adapt BESTest and Mini-BESTest to Spanish (from Spain, Europe) and investigate its validity in elderly healthy subjects without apparent difficulties in balance and locomotion. Secondly, we aimed to study with both instruments the effect of sex-gender in balance.

We hypothesized that BESTest and Mini-Bestest would highly correlate with the Berg Balance Scale (BBS) and would have a low correlation with self-assessed fear of falling in healthy older adults measured by means of Falls Efficacy Scale-International (FES-I).

\section{Methods \\ Study design}

A cross-sectional transcultural adaptation and validation study design was used.

\section{Participants}

Participants were 30 community-dwelling elderly subjects (14 males and 16 females) (mean age: 73.3, range: 65-89) recruited with a convenience sampling. Inclusion criteria were: (1) no present health problems relating to balance disturbances; (2) no history of falling in the last three months; (3) the ability to walk $6 \mathrm{~m}$ without orthopaedic devices or the assistance from another person; (4) cognitively able to receive three verbal instructions; (5) capable to perform tests without excessive fatigue.

The study followed the Declaration of Helsinki and all the participants received oral and written information about the study and signed the informed consent. Ethical approval was obtained from the Comité Etico de Investigación de Aragón - Spain (CEICA). 


\section{Clinical scales}

The BESTest is a 27-item test organized in six sections, using a model of motor control as a theoretical framework [1]. Each item is scored from 3 (normal) to 0 (severe, not capable) points based on time or performance criteria resulting in a total possible score of 108 points, which are converted to a percentage score. Higher scores indicate better balance.

Items are grouped into 6 systems called "Biomechanical Constraints", "Stability Limits/Verticality", "Anticipatory Postural Adjustments", "Postural Responses", "Sensory Orientation" and "Stability in Gait".

The mini-BESTest was developed using factor analysis to identify the items of the BESTest that represented dynamic balance, eliminating redundant and insensitive items from the BESTest [5]. It includes tasks from the BESTest sections "Anticipatory Postural Adjustments", "Postural Responses", "Sensory Orientation" and "Stability in Gait", and comprises 14 items scored from 2 (normal) to 0 (severe, not capable), resulting in a total possible score of 28 points, where higher scores indicate better balance.

The BBS consists of 14 functional balance items that focus on static and dynamic balance abilities. Each item is scored from 4 (normal function) to 0 (impossible). The total possible score is 56 points. The interpretation of the result is: $\leq 20$ - wheelchair user, $>20 \leq 40$ - walking with assistance, $>40 \leq 56$ - independent. A score lower than 46 points indicates that the person has a high risk of falling [10].

The FES-I system measures the level of confidence shown by the subject in carrying out basic activities of daily life. It comprises 16 items with a Likert scale of 4 . The total possible score is 64 points. Higher scores indicate worse balance [19].

\section{Transcultural translation process}

For the translation of BESTest, Mini-BESTest and their respective instructions, the Beaton recommendations were followed [17]. Firstly, two qualified people translated both instruments from English to Spanish. Then a certified translator back translated the tests to English. The original author of the tests, Fay Horak, reviewed and commented both English documents. All corrections were translated to Spanish and integrated in the managed balance tests. The International System of Units was adopted in the Spanish version of both tests, converting pounds into kilograms and feet and inches into centimetres. Results were rounded off to the nearest unit. A group of physiotherapists instructed in BESTest and Mini-BESTest assessment reviewed the final versions and followed a pre-test study at the Hospital Universitario Miguel Servet (Zaragoza, Spain) with neurological patients and 12 community-dwelling elderly healthy subjects. This training period allowed adjustment of a minor number of instructions to improve items understanding in the cultural context.

\section{Validation procedure}

Feasibility analysis was not necessary because these measurement systems are already applied and validated in other languages $[20,21]$.

Two trained senior physiotherapists assessed the 30 subjects by means of the BESTest and Mini-BESTest, the BBS and FES-I. Redundant items of BBS and BESTest were assessed together. The Mini-BESTest scores were rated simultaneously with the BESTest scores, so that the corresponding test was only applied once for each subject.

Evaluations were made at the home of each subject, where required clinical equipment was taken. The full session lasted approximately $45 \mathrm{~min}$. The BERG scale was always administered before BESTest; FES-I was fulfilled at the beginning or at the end of the assessment. To avoid fatigue of participants, both physiotherapists scored each item at the same time without communication between them.

The data capture period of the study lasted two months.

\section{Data analysis}

Descriptive statistics were first calculated for age, height, weight and each of the measures with 95\% confidence interval (CI) when applicable. Cronbach Alpha was calculated to assess internal consistency of BESTest and mini-BESTest. Values higher than 0.70 were considered to indicate internal consistency of scales. Reliability was calculated via Intraclass correlation coefficient (ICC) and 95\% CI using analysis of variance models. Consistent with previous work, an ICC was defined as (1) very good or excellent $>0.75$; (2) good, 0.74 to 0.60 ; (3) fair, 0.59 to 0.40 ; and (4) poor, <0.4 [22, 23] . Minimum detectable change (MDC) was calculated starting from the standard error of the measurement and taking into account the standard deviation of the values of all the participants. A 95\% CI was applied to calculate the formula.

The Pearson correlation coefficient was calculated to examine criteria validity by comparing the relationship between the BESTest, mini-BESTest, BBS and FES-I. A correlation ( $\mathrm{r}$ value) between 0 and 0.25 was interpreted as little or no relationship, between 0.25 and 0.5 as a fair relationship, between 0.50 .75 as moderate, and above 0.75 as a very good to excellent relationship.

The presence of floor and ceiling effects was defined as $15 \%$ or more of the participants having the lowest or respectively the highest possible score on the BESTest and the Mini-BESTest [24].

All analyses were conducted with SPSS software, version 22.0 (IBM Statistic for Windows. Armonk, NY: 
IBM Corp.). The effect of sex-gender was analysed after verifying the variables normal distribution using oneway ANOVA. $\mathrm{TIBCO}^{\circ}$ Data Science - Statistica ${ }^{\circ}$ was used for this last analysis.

\section{Results}

30 people participated in the study, 14 were men (46.7\%) and 16 women (53.3\%). They were aged 65 to 89 years old. None of the participants used walking aids. Our cohort do not present anthropometric differences depending on gender (Table 1).

Table 1 presents the BBS and FES-I scores as the parameters that illustrate the balance status of our cohort and their own perception about risk of falling. BBS showed significant differences between men (51.3 (1.4)) and women (49.10 (3.40)), $(\mathrm{F}(1.28)=5.07, p<0.03$, Table 1$)$. Only 3 people (all woman) showed a BBS score under 46, meaning that our cohort had a high risk of falling, although they had not reported falls in the last three months.

None of the participants got the lowest or highest possible score at the BESTest and Mini-BESTest, so no floor or ceiling effects were detected.

The total score (\%) for BESTest obtained by the second rater presented a significantly higher score for men than for women $(\mathrm{F}(2.27)=5.28, p=0.01$, Table 2).

There was a significant difference between groups (women and men) $(\mathrm{F}(2.27)=4.50, p=0.02$, Table 2) but only for the first rater $(p<0.01)$.

When analysing the BESTest section scores disaggregated by gender, scores obtained by women were lower than those reached by men, regardless of the BESTest or Mini-BESTest section. ANOVA showed a significant difference depending on gender in sections I, IV and VI. Values at section I (Biomechanical Constraints) were $\mathrm{F}(2.27)=3.22, p=0.06$. The mean differences were 1.9 $(p<0.03)$ obtained by rater 1 and $1.9(p<0.02)$ by rater 2 (Table 2). This difference represents $14 \%$ of the maximal score of section I.

In section IV (Postural Responses), the value was $\mathrm{F}(2$. $27)=4.48, p=0.02$ for both raters (Scheffé post-hoc for both raters was $p<0.01$ ). This difference represents $10 \%$ of the maximal score of the Postural Responses section.
Also in section VI (Stability of Gait), ANOVA showed an $\mathrm{F}(2.27)=3.47, p=0.05$ but only for scores registered by the second rater (Scheffé post-hoc for rater $1 \mathrm{p}<0.01$, rater $2 p<0.07$ ).

For Mini-BESTest, scores obtained by women were also lower than those reached by men in all sections and for both raters (Table 2).

\section{Internal consistency reliability}

BESTest and Mini-BESTest showed a good internal consistency, with Cronbach alpha values between 0.79 and 0.98 (Table 3).

\section{Inter-rater reliability}

The BESTest total score showed excellent inter-rater agreement $(\mathrm{ICC}=0.97,95 \% \mathrm{CI}, 0.93-0.98$, Table 4, Fig. 1). Also excellent was inter-rater reproducibility for the total score of Mini-BESTest (ICC $=0.79,95 \% \mathrm{CI}$ 0.38-0.82, Table 4, Fig. 1). All sections of the BESTest and the Mini-BESTest similarly showed excellent interrater reliability (Table 3, Figs. 2, 3). The highest ICC average was for Anticipatory postural adjustments (ICC $=0.98,95 \%$ CI $0.96-0.99$ for BESTest and $\mathrm{ICC}=$ 0.94, 95\% CI 0.88-0.97 for Mini-BESTest, Table 3).

\section{Validity}

There was a strong positive and statistically significant correlation between the total scores of BESTest and Mini-BESTest $(r=0.65 ; p<0.001$, Table 4). Correlations between corresponding sections of both systems were strongly positive and statistically significant (Table 4).

Discriminating by gender, all sections correlated strongly and obtained statistical significance. Higher correlation was observed in the sensory orientation section, being higher in men $(r=0.98$ and 0.90 respectively; $\mathrm{p}<$ 0.001 , Table 4). There was a moderate correlation in women's postural responses $(\mathrm{r}=0.44, p<0.05$, Table 4$)$.

BESTest had a moderate association with BBS $(r=$ 0.43 , p 0.02 , Table 5) and a strong association with FESI with statistical significance $(r=0.90)$. Mini-BESTest had a fair correlation with BBS and FES-I. There was no

Table 1 Characteristics of the study population and measures of the BBS and FES-I central tendency

\begin{tabular}{|c|c|c|c|c|c|c|c|}
\hline \multirow{2}{*}{$\begin{array}{l}\text { Measure } \\
\text { (units) }\end{array}$} & \multicolumn{2}{|c|}{ Total cohort $(n=30)$} & \multicolumn{2}{|l|}{ Men $(n=14)$} & \multicolumn{2}{|c|}{ Women $(n=16)$} & \multirow[t]{2}{*}{$\mathrm{F}[2,25]$ and $p$ values } \\
\hline & Mean (SD) & Min-max (Cl 95\%) & Mean (SD) & $\operatorname{Min}-\operatorname{Max}(\mathrm{Cl}$ 95\%) & Mean (SD) & Min-Max (Cl 95\%) & \\
\hline ge (y) & $73(6.2)$ & $65-89(70.7-75.3)$ & $72.71(7.12)$ & $65-89(68-78.6)$ & $73.25(5.52)$ & $65-83(70.3-76.2)$ & $0.05(0.82)$ \\
\hline Weight (Kg) & $69(13.3)$ & 49-92 (64-74) & $77.43(10.40)$ & $62-92(68.3-81.5)$ & $61.63(11.11)$ & $49-86(55.7-67.5)$ & $16.02(0.00)^{*}$ \\
\hline Height (m) & $1.62(0.09)$ & 150-181 (159.1-165.6) & $1.68(0.08)$ & $155-181(162.3-172.9)$ & $1.57(0.05)$ & $150-170(154.1-160)$ & $16.02(0.00)^{*}$ \\
\hline BMI $\left(\mathrm{Kg} / \mathrm{m}^{2}\right)$ & $26(3.74)$ & $21-35(24.7-27.5)$ & $27.21(3.26)$ & $22-35(24.7-28.2)$ & $25.06(3.99)$ & $21-34(22.9-27.2)$ & $2.57(0.12)$ \\
\hline BBS & $50.1(2.9)$ & $43-52(48.9-51.2)$ & $51.3(1.4)$ & $48-52(50.6-52.3)$ & $49.1(3.4)$ & $43-52(47.2-50.9)$ & $5.07(0.03)^{*}$ \\
\hline FES-I & $18.7(1.9)$ & $17-26(17.9-19.5)$ & $18.1(1.5)$ & $17-22(17.1-19.1)$ & $19.1(2.2)$ & $17-26(18-20.3)$ & $1.92(0.18)$ \\
\hline
\end{tabular}

${ }^{*}$ Minimum and maximum with $95 \%$ confidence interval. ${ }^{*} p<0.05$ 
Table 2 Scores obtained by sections and total score of BESTest and Mini-BESTest. Values obtained by each raters

\begin{tabular}{|c|c|c|c|c|c|c|c|c|c|c|c|c|c|c|c|}
\hline & \multicolumn{6}{|c|}{ Rater 1} & \multirow{3}{*}{$\begin{array}{l}\text { Post-hoc } \\
\text { Scheffé }\end{array}$} & \multicolumn{6}{|c|}{ Rater 2} & \multirow{3}{*}{$\begin{array}{l}\text { Post-hoc } \\
\text { Scheffé }\end{array}$} & \multirow{3}{*}{$\begin{array}{l}F[2,25] \& \\
(p) \text { values }\end{array}$} \\
\hline & \multicolumn{2}{|c|}{$\begin{array}{l}\text { Total } \\
\text { cohort }\end{array}$} & \multicolumn{2}{|l|}{ Men } & \multicolumn{2}{|c|}{ Women } & & \multicolumn{2}{|c|}{$\begin{array}{l}\text { Total } \\
\text { cohort } \\
\end{array}$} & \multicolumn{2}{|l|}{ Men } & \multicolumn{2}{|c|}{ Women } & & \\
\hline & Mean & SD & Mean & SD & Mean & SD & & Mean & SD & Mean & SD & Mean & SD & & \\
\hline I. Biomechanical Constraints & 9.97 & 2.47 & 11.00 & 2.45 & 9.06 & 2.17 & $(0.03)^{*}$ & 10.20 & 2.20 & 11.21 & 2.04 & 9.31 & 1.99 & $(0.01)^{*}$ & $3.22(0.06)$ \\
\hline II. Stability limits/Verticality & 18.57 & 1.85 & 19.14 & 1.35 & 18.06 & 2.11 & NS & 18.43 & 1.94 & 18.71 & 1.81 & 18.19 & 2.10 & NS & $1.82(0.18)$ \\
\hline III. Anticipatory Postural Adjustments & 15.73 & 1.18 & 16.07 & 1.73 & 15.44 & 1.90 & NS & 15.70 & 1.72 & 16.07 & 1.68 & 15.38 & 1.75 & NS & $0.68(0.52)$ \\
\hline IV. Postural Responses & 14.93 & 1.82 & 15.79 & 1.31 & 14.19 & 1.90 & $(0.01)^{*}$ & 14.03 & 1.92 & 15.0 & 1.75 & 13.19 & 1.68 & $(0.01)^{*}$ & $4.48(0.02)^{*}$ \\
\hline V. Sensory Orientation & 13.63 & 1.35 & 13.71 & 1.64 & 13.56 & 1.10 & NS & 13.63 & 1.35 & 13.64 & 1.65 & 13.63 & 1.10 & NS & $0.24(0.78)$ \\
\hline VI. Stability in Gait & 18.07 & 1.82 & 18.71 & 1.77 & 17.50 & 1.71 & $(0.02)^{*}$ & 18.47 & 1.78 & 19.29 & 1.27 & 17.75 & 1.88 & $(0.07)$ & $3.47(0.05)^{*}$ \\
\hline BESTest total score 0-108 & 90.90 & 6.80 & 94.43 & 6.03 & 87.81 & 6.01 & & 90.47 & 6.21 & 93.93 & 5.91 & 87.44 & 4.83 & & \\
\hline BESTest $(0-108) / 108 * 100$ & 84.17 & 6.30 & 84.59 & 6.49 & 83.80 & 6.32 & $(0.74)$ & 83.77 & 5.75 & 86.97 & 5.48 & 80.96 & 4.47 & $(0.01)^{*}$ & $5.28(0.01)^{*}$ \\
\hline I. Anticipatory postural adjustments & 6.57 & 1.16 & 6.78 & 1.19 & 6.37 & 1.15 & NS & 6.53 & 1.22 & 6.79 & 1.25 & 6.31 & 1.19 & NS & $0.54(0.59)$ \\
\hline II. Postural responses & 7.03 & 0.96 & 7.28 & 0.99 & 6.81 & 0.91 & NS & 6.50 & 0.82 & 6.71 & 0.82 & 6.31 & 0.79 & NS & $1.08(0.35)$ \\
\hline III. Sensory orientation & 5.03 & 0.96 & 5.21 & 1.05 & 4.87 & 0.88 & NS & 5.03 & 1.03 & 5.07 & 1.14 & 5.00 & 0.97 & NS & $0.72(0.50)$ \\
\hline IV. Stability in gait & 8.13 & 1.01 & 8.57 & 0.94 & 7.75 & 0.93 & NS & 8.20 & 1.41 & 8.57 & 1.28 & 7.87 & 1.09 & NS & $2.86(0.07)$ \\
\hline Mini-BESTest & 21.1 & 1.6 & 21.93 & 1.38 & 20.37 & 1.45 & $(0.01)^{*}$ & 20.8 & 2.0 & 21.36 & 2.50 & 20.31 & 1.45 & $(0.17)$ & $4.5(0.02)^{*}$ \\
\hline
\end{tabular}

NS not significant. ${ }^{*} p<0.05$

Table 3 Inter-rater concordance in each BESTest section and for each Mini-BESTest items

\begin{tabular}{|c|c|c|c|c|c|}
\hline & ICC Unique M $(95 \% \mathrm{Cl})^{\mathrm{a}}$ & ICC Average M $(95 \% \mathrm{Cl})^{\mathrm{b}}$ & Alfa Cronbach & SEM $^{c}$ & $\overline{M D C^{d}}$ \\
\hline \multicolumn{6}{|l|}{ BESTest } \\
\hline Section I. Biomechanical constraints & $0.88(0.76-0.94)$ & $0.94(0.86-0.97)$ & 0.93 & 0,61 & 1,68 \\
\hline Section II. Stability limits/verticality & $0.81(0,64-0,90)$ & $0,79(0,78-0,95))$ & 0.90 & 0,85 & 2,35 \\
\hline Section III. Anticipatory postural adjustments & $0.96(0.92-0.98)$ & $0.98(0.96-0.99)$ & 0.98 & 0,26 & 0,71 \\
\hline Section IV. Postural responses & $0.73(0.51-0.82)$ & $0.84(0.67-0.93)$ & 0.84 & 0,73 & 2,02 \\
\hline Section V. Sensory orientation & $0.92(0.85-0.96)$ & $0.96(0.92-0.98)$ & 0.96 & 0,27 & 0,75 \\
\hline Section VI. Stability in gait & $0.89(0.78-0.94)$ & $0.94(0.87-0.97)$ & 0.94 & 0,45 & 1,23 \\
\hline Total Score & $0.93(0.86-0.97)$ & $0.97(0.93-0.98)$ & 0.97 & 1,18 & 3,27 \\
\hline \multicolumn{6}{|l|}{ Mini-BESTest } \\
\hline Anticipatory & $0.89(0.78-0.95)$ & $0.94(0.88-0.97)$ & 0.94 & 0,29 & 0,79 \\
\hline Reactive postural control & $0.67(0.41-0.83)$ & $0.80(0.58-0.90)$ & 0.80 & 0,43 & 1,19 \\
\hline Sensory orientation & $0.72(0.50-0.86)$ & $0.84(0.66-0.92)$ & 0.84 & 0,39 & 1,07 \\
\hline Dynamic gait & $0.78(0.59-0.89)$ & $0.88(0.74-0.94)$ & 0.88 & 0,35 & 0,97 \\
\hline Total score & $0.65(0.38-0.82)$ & $0.79(0.55-0.90)$ & 0.79 & 0,74 & 2,04 \\
\hline
\end{tabular}

${ }^{a}$ Intraclass Correlation Coeficient Unique Measurement (95\% Confidence Interval)

${ }^{\mathrm{b}}$ Intraclass Correlation Coeficient Average Measurement (95\% Confidence Interval)

'Standard Error of Measurement

${ }^{\mathrm{d}}$ Minimum Detectable Change 
Table 4 Correlation between sections of BESTest and MiniBESTest

\begin{tabular}{llll}
\hline & $\begin{array}{l}\text { Women } \\
\text { (Pearson's r) }\end{array}$ & $\begin{array}{l}\text { Men } \\
(\text { Pearson's r) }\end{array}$ & $\begin{array}{l}\text { Total } \\
\text { (Pearson's r) }\end{array}$ \\
\hline Anticipatory & $0.93^{*}$ & $0.87^{*}$ & $0.90^{*}$ \\
Postural responses & $0.44^{\dagger}$ & $0.76^{\dagger}$ & $0.59^{*}$ \\
Sensory orientation & $0.90^{*}$ & $0.98^{*}$ & $0.94^{*}$ \\
Dynamic gait & $0.88^{*}$ & $0.94^{*}$ & $0.92^{*}$ \\
Total score & $0.51^{\dagger}$ & $0.56^{\dagger}$ & $0.65^{*}$ \\
\hline
\end{tabular}

${ }^{*} \mathrm{p}<0.001$

$\mathrm{tp} \leq 0.05$ correlation between Mini-BESTest and BBS in the case of women (Table 5).

\section{Discussion}

This study aimed to verify psychometric properties of BESTest and Mini-BESTest once translated to Spanish in a community-based sample of older people without related balance problems and secondarily to study sexgender differences. Validation was done by comparing to BBS and FES-I.

Our results showed that the Spanish translated version of BESTest and Mini-BESTest are reliable and valid measures of balance performance for communitydwelling elderly people not prone to falling, and that scores of BESTest and Mini-BESTest obtained by women were lower than the ones obtained by men. Data
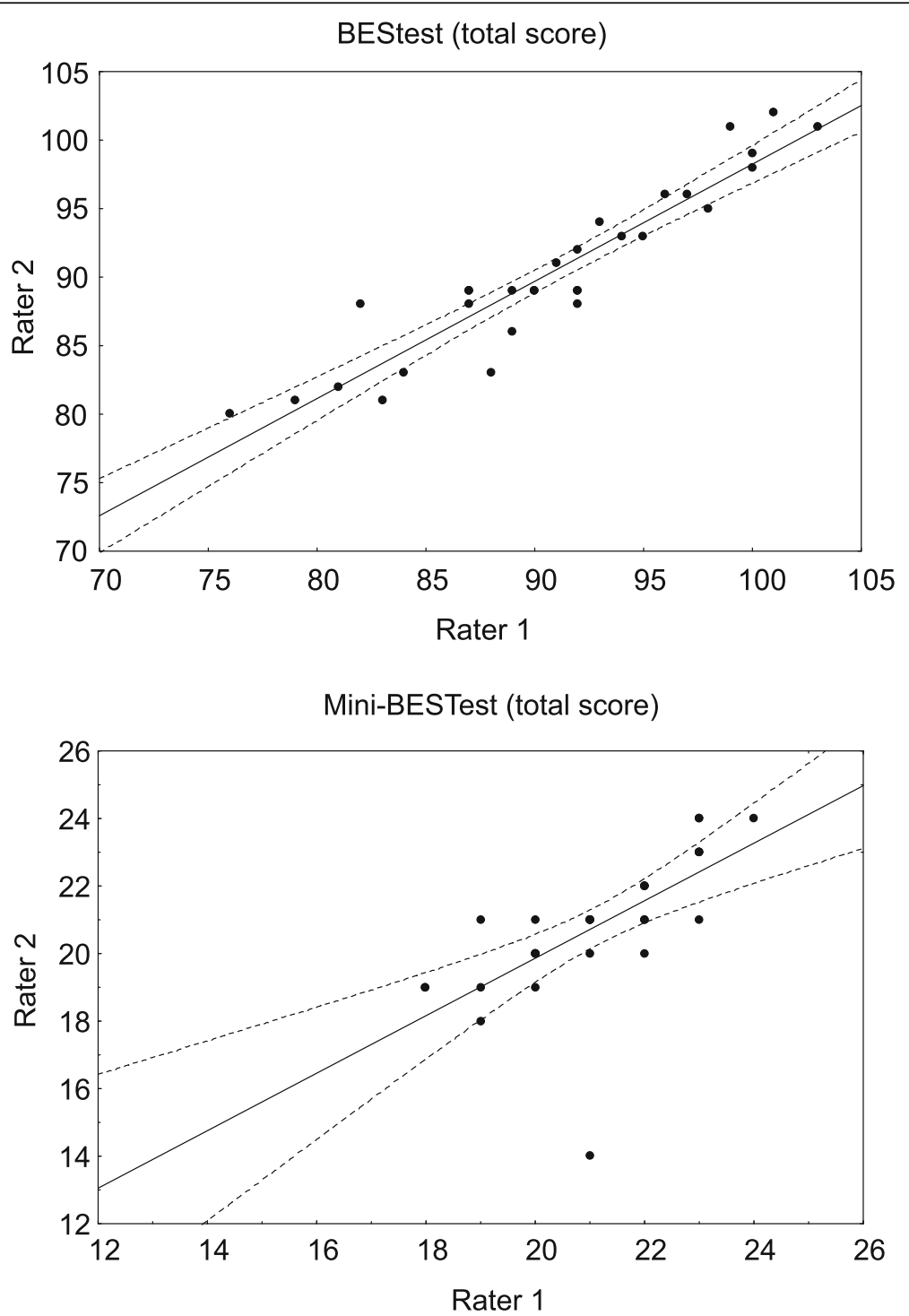

Fig. 1 The BESTest total score inter-rater agreement 

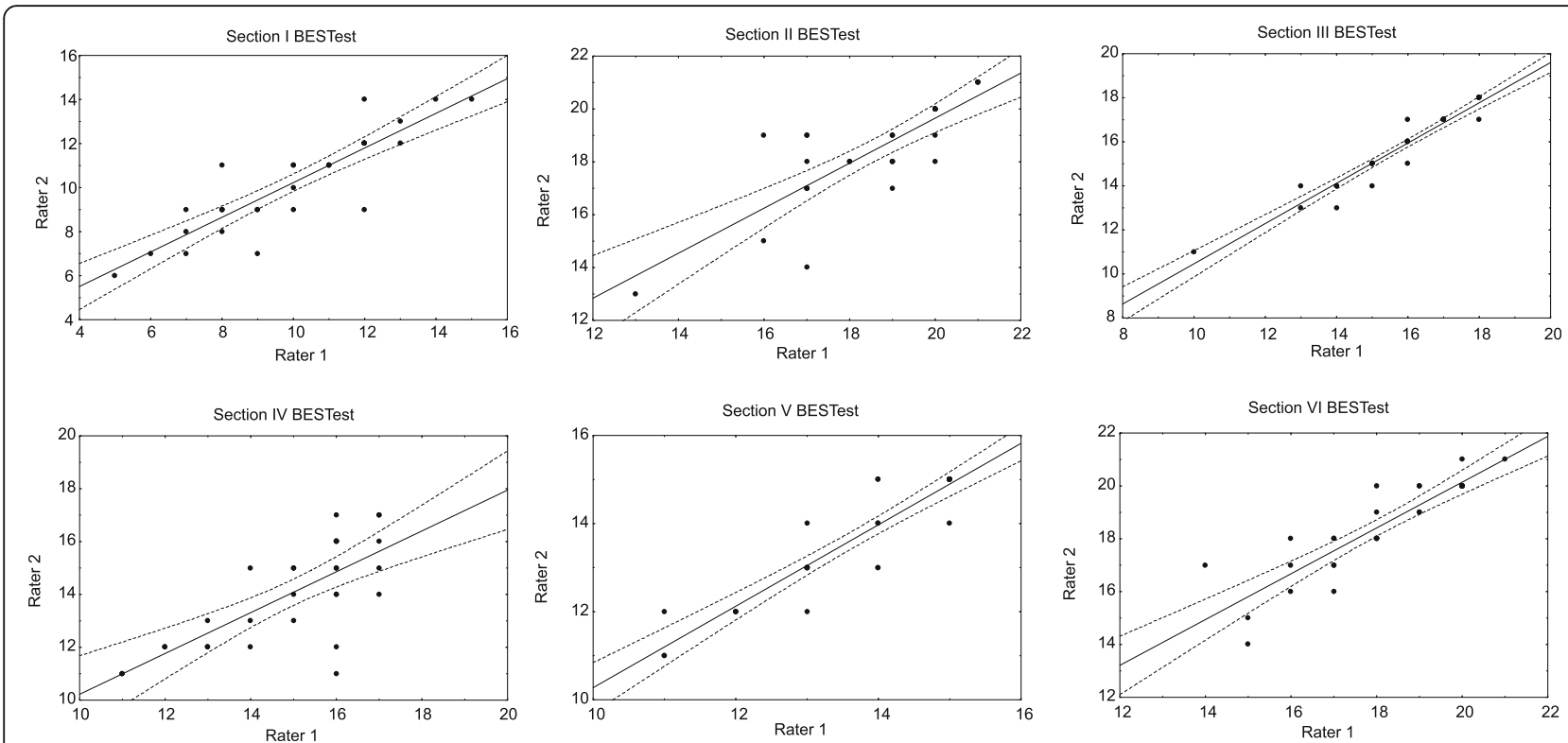

Fig. 2 Inter-rater reliability in the BESTest sections
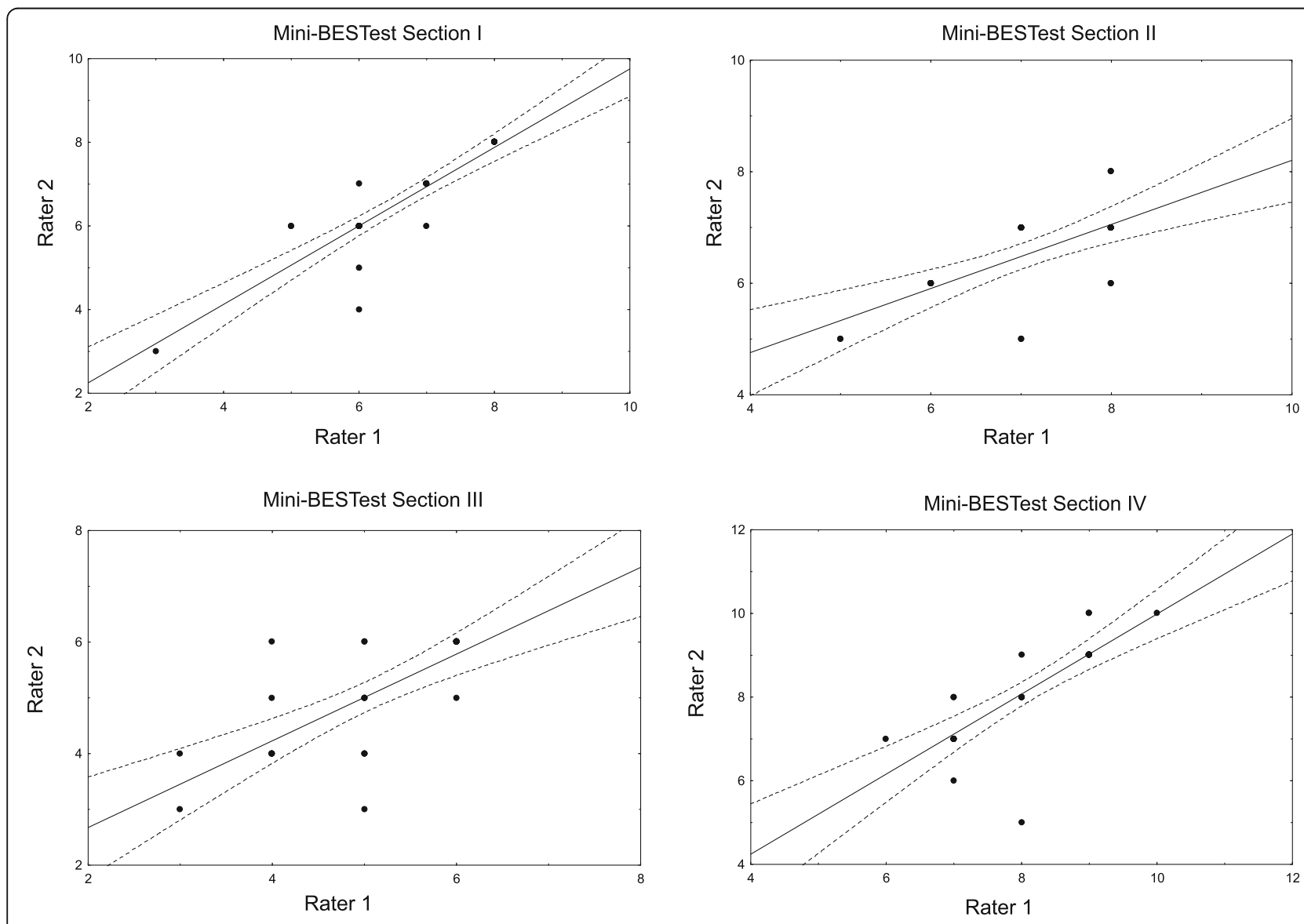

Fig. 3 Inter-rater reliability in the Mini-BESTest sections 
Table 5 Correlations between BESTest and MiniBest with BBS and FES-I

\begin{tabular}{llll}
\hline Scale & \multicolumn{1}{l}{$\begin{array}{l}\text { Women } \\
\text { Pearson's r }(p \text { value) }\end{array}$} & $\begin{array}{l}\text { Men } \\
\text { Pearson's r }(p \text { value) })\end{array}$ & $\begin{array}{l}\text { Total } \\
\text { Pearson's r ( } p \text { value) }\end{array}$ \\
\hline BESTest & & & \\
FES-I & $0.21(0.44)$ & $0.48(0.14)$ & $0.90(0.65)$ \\
BBS & $0.44(0.10)$ & $-0.01(0.96)$ & $0.43(0.02)^{*}$ \\
MINIBest & & & \\
FES-I & $-0.14(0.60)$ & $0.22(0.51)$ & $-0.18(0.37)$ \\
BBS & $0.003(0.90)$ & $-0.18(0.53)$ & $0.18(0.35)$ \\
\hline
\end{tabular}

"Significant correlation $(p<0.05)$

obtained in the BESTest showed similar results for the central tendency indicators than those obtained in previous studies performed by Anson and O'Hoski [5, 7]. Both balance measurement systems showed a good internal consistency for items in respect of the total score and for each of the six sections of BESTest and the four of the Mini-BESTest, also demonstrating that the items measured the same underlying attribute. O'Hosky et al. [5], showed that the BESTest, mini-BESTest and briefBESTest present the construct validity for assessing balance in adults aged over 50 years. We also found a greater degree of agreement between raters for the BESTest validity, indicated by excellent inter-rater reliability for total score and for test subsections. Values for ICC in all sections, except Postural responses, were similar to those obtained by Padgett or Wang-Hsu [23, 25]. Reliability in Mini-BESTest indicated excellent interrater concordance data, although with lower scores in some sections than those registered in people with chronic stroke or Parkinson's disease [11, 22, 26]. Positive correlations between BESTest and Mini-BESTest were found, as obtained by other studies with the same scales developed in other languages $[16,18]$.

Scores of BESTest and Mini-BESTest obtained by women were lower than men. There is strong evidence that physical activity reduces the risk of falling [27, 28]. Some papers have also pointed out that physical activity is more intense and frequent in elderly men, while activities of daily living are usually more demanding for women [29]. Unfortunately, in our study we have not recorded a validated score for physical activity, but the participants who were men reported practicing more physical activity than women. This is the only factor that could explain our results. Comorbidity, medication or socioeconomic differences, other important-factors mentioned in the literature as responsible for poor balance [29-31] should not be taken into account in our present work because we selected for healthy subjects, unhealthy were excluded, and they were mostly couples with a similar socioeconomic status. Nevertheless, despite the oral report of physical activity, due to the absence of a systematic collection of this information through selfreports or administered scales, we consider that one should take with caution the interpretation that the differences in balance score between genders is due to differences in levels of physical activity. Those differences observed in all the test when disaggregating data by sex require further research.

At the criterion validity and correlating with BBS, a significant correlation was found with BESTest and a fair one with Mini-BESTest, obtaining an inverse correlation in men, as in other research [5]. It could be asked if, in relation to the BESTest and BBS, this inverse correlation is only in any person with good balance or especially in men because, as some studies point out, they have better balance. Those results suggest that other measurement systems should be included to identify in a more accurate and sensitive way individuals with functional limitations beyond BBS [10, 11]. Fear of falling measured by FES-I showed a strong association with BESTest, although this was not statistically significant. Regarding the Mini-BEST, in the total sample a negative correlation was observed with FES-I, so the risk of falling decreased when dynamic scores in balance increased, as expected [13, 32]. BESTest correlated positively and strongly with Mini-BESTest, but this correlation was inverse. It could be that aspects that the Mini-BESTest fails to evaluate, that are included in the BESTest, make this assessment less accurate in people who are afraid of falling. This situation is particularly important in the group of women, since in men the correlation does not have a positive sign. In general, we have observed that the correlation between the scales used in this study is greater the worse the balance is. To detect which aspects of balance can be improved in the healthy ageing population, it would be the BESTest that detects more precisely these difficulties. This is especially true in the diagnosis and treatment of balance problems considering the differences observed between women and men. We want to highlight these results, which lead us to ask ourselves if better balance in independent elderly people who have no history of a recent fall is linked to gender. There is no consensus in the literature: some studies did not find them, while others observed indeed lower levels of postural stability and balance for men [29-31].

It would be also crucial to identify those factors that decrease or increase risk of falling and that contribute to maintaining functional independence.

\section{Study limitations and directions for future research}

The not-fully-random sampling that was adopted for practical reasons limits the strength with which these results can be used to infer properties of the general population. 
This study was designed to assess the psychometric properties of BESTest and Mini-BESTest in communitydwelling elderly people in Spanish. However, given the differences obtained in the correlations between BESTest and MiniBESTest and FES-I or BBS when disaggregating data by gender, it should be studied if, at similar ages, the same level of physical activity in that population implies a similar quality of balance. This would require a larger sample size than the one in the present study.

We strongly recommend cultural adaptation to other Spanish-speaking countries, especially in Central and South America.

\section{Conclusions}

Spanish versions of BESTest and Mini-BESTest are balance systems comprehensible for new raters. The BESTest and Mini-BESTest are valid and reliable tools to provide information on which particular balance systems were the underlying cause of balance impairments in community dwelling older adults. Our results suggest that elderly women showed a worse quality of balance and a greater perception of their risk of falling than men.

\section{Abbreviations}

BESTest: Balance Evaluation Systems Test; BBS: Berg Balance Scale; CEICA: Comité Ético de Investigación de Aragón-Spain; Cl: Confidence Interval; FES-I: Falls Efficacy Scale International; ICC: Intraclass Correlation Coefficient; MDC: Minimum Detectable Change

\section{Acknowledgments}

The authors thank all participants and translator Daniel Bolea-Moll. We also thank Dr. Fay Horak for inviting us to translate BESTest and Mini-BESTest. This work was supported by the Research Fund of the Université Libre de Bruxelles (Belgium).

\section{License for administration of questionnaires}

No one of the questionnaires or measures used in our study require a license in order to administer them.

\section{Authors' contributions}

Research design: PD, AB. Writing: PD, AG, AB. Data collection: PD, EA. Data analysis: AG, AB. Revision: PD, AB. All authors have approved the submitted versión. They have agreed both to be personally accountable for the author's own contributions. All authors know that questions related to the accuracy or integrity of any part of the work, even ones in which the author was not personally involved, are appropriately investigated, resolved, and the resolution documented in the literature.

\section{Funding}

Not applicable.

\section{Availability of data and materials}

The datasets analysed during the current study are available from the corresponding author on reasonable request.

\section{Ethics approval and consent to participate}

The study followed the Declaration of Helsinki and all the participants received oral and written information about the study and signed the informed consent. Ethical approval was obtained from the Comité Etico de Investigación de Aragón - Spain (CEICA).

\section{Consent for publication}

Not applicable.

\section{Competing interests}

The authors declare that they have no competing interests.

\section{Author details}

'IIS Aragón, Facultad de Ciencias de la Salud, Universidad de Zaragoza, Zaragoza, Spain. ${ }^{2}$ Hospital Universitario Miguel Servet, Zaragoza, Spain.

${ }^{3}$ Unité de Recherche en Sciences de I'Ostéopathie (URSO). Faculté des Sciences de la Motricité, Université Libre de Bruxelles (ULB), Brussels, Belgium. ${ }^{4}$ Instituto de Investigación Sanitaria Biocruces Bizkaia, Barakaldo, Spain.

Received: 11 January 2020 Accepted: 19 August 2020

Published online: 04 November 2020

\section{References}

1. Horak FB, Wrisley DM, Frank J. The balance evaluation systems test (BESTest) to differentiate balance deficits. Phys Ther. 2009 May;89(5):484-98.

2. Lacour M, Dutheil S, Tighilet B, Lopez C, Borel L. Tell me your vestibular deficit, and I'll tell you how you'll compensate. Ann N Y Acad Sci. 2009 May; 1164:268-78.

3. Wiesmeier IK, Dalin D, Maurer C. Elderly use proprioception rather than visual and vestibular cues for postural motor control. Front Aging Neurosci. 2015;7:97.

4. Borel L, Alescio-Lautier B. Posture and cognition in the elderly: Interaction and contribution to the rehabilitation strategies. Neurophysiologie Clinique/ Clinical Neurophysiology; Special issue from Société francophone Posture, Equilibre et Locomotion - 1er et 2nd congrès de la SOFPEL, décembre 2012 Marseille, décembre 2013. Genève. 2014;44(1):95-107.

5. O'Hoski S, Sibley KM, Brooks D, Beauchamp MK. Construct validity of the BESTest, mini-BESTest and briefBESTest in adults aged 50 years and older. Gait Posture. 2015;42(3):301-5.

6. Gale CR, Cooper C, Aihie SA. Prevalence and risk factors for falls in older men and women: the English longitudinal study of ageing. Age Ageing 2016;45(6):789-94.

7. Anson E, Thompson E, Ma L, Jeka J. Reliability and Fall Risk Detection for the BESTest and Mini-BESTest in Older Adults. J Geriatr Phys Ther. 2019;42(2):8185.

8. Latheef A, Thangadurai C, Moham S. Evaluation of age and gender-related balance scores in normal adults using Mini Balance Evaluation Systems Test. Int J Physiother. 2017;4(3):196-200.

9. Taghizadeh G, Martinez-Martin P, Fereshtehnejad SM, Habibi SA, Nikbakht N, Alizadeh NH, et al. Psychometric properties of the Berg balance scale in idiopathic Parkinson' disease in the drug off-phase. Neurol Sci. 2018 Dec; 39(12):2175-81.

10. Blum L, Korner-Bitensky N. Usefulness of the Berg balance scale in stroke rehabilitation: a systematic review. Phys Ther. 2008 May;88(5):559-66.

11. Charlotte SL, Tsang L-RL, Chung RCK, Marco YC. Pang. Psychometric Properties of the Mini-Balance Evaluation Systems Test (Mini-BESTest) in CommunityDwelling Individuals With Chronic Stroke. Phys Ther. 2013;93(8):1102-15.

12. Silva A, Vaughan-Graham J, Silva C, Sousa A, Cunha C, Ferreira R, et al. Stroke rehabilitation and research: consideration of the role of the corticoreticulospinal system. Somatosens Mot Res. 2018;35(2):148-52.

13. Del-Río-Valeiras M, Gayoso-Diz P, Santos-Pérez S, Rossi-lzquierdo M, FaraldoGarcía A, Vaamonde-Sánchez-Andrade I, et al. Is there a relationship between short FES-I test scores and objective assessment of balance in the older people with age-induced instability? Arch Gerontol Geriatr. 2015;62: 90-6.

14. Aibar-Almazán A, Martínez-Amat A, Cruz-Díaz D, Jiménez-García JD, Achalandabaso A, Sánchez-Montesinos I, et al. Sarcopenia and sarcopenic obesity in Spanish community-dwelling middle-aged and older women: association with balance confidence, fear of falling and fall risk. Maturitas. 2018 Jan;107:26-32.

15. Bergström M, Lenholm E, Franzén E. Translation and validation of the Swedish version of the mini-BESTest in subjects with Parkinson's disease or stroke: a pilot study. Physiother Theory Pract. 2012 Oct; 28(7):509-14.

16. Chinsongkram B, Chaikeeree N, Saengsirisuwan V, Viriyatharakij N, Horak $F B$, Boonsinsukh R. Reliability and validity of the balance evaluation systems test (BESTest) in people with subacute stroke. Phys Ther. 2014 Nov;94(11):1632-43. 
17. Beaton DE, Bombardier C, Guillemin F, Ferraz MB. Guidelines for the process of cross-cultural adaptation of self-report measures. Spine. 2000; 25(24):3186-91.

18. Ramada-Rodilla JM, Serra-Pujadas C, Delclos-Clanchet GL. Cross-cultural adaptation and health questionnaires validation: revision and methodological recommendations. Salud Publica Mex. 2013 February 01; 55(1):57-66.

19. Delbaere K, Close JCT, Mikolaizak AS, Sachdev PS, Brodaty H, Lord SR. The Falls Efficacy Scale International (FES-I). A comprehensive longitudinal validation study. Age Ageing. 2010;39(2):210-6.

20. Maia AC, Rodrigues-de-Paula F, Magalhaes LC, Teixeira RL. Cross-cultural adaptation and analysis of the psychometric properties of the balance evaluation systems test and MiniBESTest in the elderly and individuals with Parkinson's disease: application of the Rasch model. Braz J Phys Ther. 2013; 17(3):195-217.

21. Franchignoni F, Horak F, Godi M, Nardone A, Giordano A. Using psychometric techniques to improve the balance evaluation systems test: the mini-BESTest. J Rehabil Med. 2010 April 01;42(4):323-31.

22. Leddy AL, Crowner BE, Earhart GM. Utility of the mini-BESTest, BESTest, and BESTest sections for balance assessments in individuals with Parkinson disease. J Neurol Phys Ther. 2011 Jun;35(2):90-7.

23. Padgett PK, Jacobs JV, Kasser SL. Is the BESTest at its best? A suggested brief version based on interrater reliability, validity, internal consistency, and theoretical construct. Phys Ther. 2012 Sep;92(9):1197-207.

24. Hamre C, Botolfsen P, Tangen GG, Helbostad JL. Interrater and test-retest reliability and validity of the Norwegian version of the BESTest and miniBESTest in people with increased risk of falling. BMC Geriatr. 2017;17(1):92.

25. Wang-Hsu E, Smith SS. Interrater and test-retest reliability and minimal detectable change of the balance evaluation systems test (BESTest) and subsystems with community-dwelling older adults. J Geriatr Phys Ther. 2018;41(3):173-9.

26. Godi M, Franchignoni F, Caligari M, Giordano A, Turcato AM, Nardone A. Comparison of reliability, validity, and responsiveness of the mini-BESTest and Berg balance scale in patients with balance disorders. Phys Ther. 2013 Feb;93(2):158-67.

27. Dipietro L, Campbell W, Buchner D, Kirk E, Powell K, Bloodgood B, et al. Physical activity, injurious falls, and physical function in aging: an umbrella review. Med Sci Sports Exerc. 2019;51(6):1303-13.

28. Pedrero-Chamizo R, Gómez-Cabello A, Delgado S, Rodríguez-Llarena S, Rodríguez-Marroyo JA, Cabanillas E, et al. Physical fitness levels among independent non-institutionalized Spanish elderly: the elderly EXERNET multi-center study. Arch Gerontol Geriatr. 2012;55(2):406-16.

29. Tangen GG, Robinson HS. Measuring physical performance in highly active older adults: associations with age and gender? Aging clinical and experimental research; 2019.

30. Bryant EC, Trew ME, Bruce AM, Kuisma RM, Smith AW. Gender differences in balance performance at the time of retirement. Clin Biomech (Bristol, Avon). 2005;20(3):330-5.

31. Puszczalowska-Lizis E, Bujas P, Jandzis S, Omorczyk J, Zak M. Inter-gender differences of balance indicators in persons $60-90$ years of age. Clin Interv Aging. 2018;13:903-12

32. Soto-Varela A, Gayoso-Diz P, Rossi--zquierdo M, Faraldo-Garcia A, VaamondeSanchez-Andrade I, del Rio Valeiras $\mathrm{M}$, et al. Reduction of falls in older people by improving balance with vestibular rehabilitation (ReFOVeRe study): design and methods. Aging Clin Exp Res. 2015;27(6):841-8.

\section{Publisher's Note}

Springer Nature remains neutral with regard to jurisdictional claims in published maps and institutional affiliations.

Ready to submit your research? Choose BMC and benefit from:
- fast, convenient online submission
- thorough peer review by experienced researchers in your field
- rapid publication on acceptance
- support for research data, including large and complex data types
- gold Open Access which fosters wider collaboration and increased citations
- maximum visibility for your research: over 100M website views per year
At BMC, research is always in progress.
Learn more biomedcentral.com/submissions

